\title{
The Anthroposophy of Professor Radojčić
}

\author{
Miloš Milovanović \\ Mathematical Institute of the Serbian Academy of Sciences and Arts, Beograd, Serbia
}

\begin{abstract}
In this paper, we present life and scientific work of Dr. Miloš Radojčić (1903-1975), the professor of the University of Belgrade and corresponding member of the Serbian Academy of Science and Arts. In the background of all of Radojčić's scientific works were the doctrine of anthroposophy and geometry as its essential part. It led him to, at the time, most contemporary problems in mathematics and mathematical physics. His interest in Medieval art reveals a personality capable to unify by itself artistic and scientific worldview. His published works were digitized in 2008 at the Mathematical Institute of the Serbian Academy of Sciences and Arts and exhibited as a part of the virtual library of the National Center for Digitization. Some of his papers, both published and unpublished ones, are extremly actual and their republishing could be very important not only for scientific but also for general public as well.
\end{abstract}

Keywords: medieval art, traditional cosmology, anthroposophy

\section{Introduction}

Miloš Radojčić (1903-1975) belongs to the group of Serbian scientists of which little has been and is written about. He passed unnoticed, almost invisible through Serbian science, but only as a man — not as a scientist. His work, although still not fully evaluated, bears a mark of an ingenious personality with broad and well-founded interests ranging from mathematics and physics to philosophy, religion, and art.

Based on some of his qualities, he would be one of those intellectuals between two wars, actually in the first phase of that period, who appreciated and nourished not only their field of study but also the general culture. That circle of people brought a new spirit to our milieu, the spirit that was later pushed out by narrow specialists. The broadness of the view made those people appreciate not only their own science but other values as well, and made them look at their own results with modesty, with more doubts about their real significance. This broadness is reflected in Radojčić as an artistic talent that he exhibited as he engaged in music as an amateur, in art almost as a professional, in poetry, but also in philosophy and science, since everything he did was imbued with threads of an artistic soul, refined to the utmost sensitivity.

\section{Life and Scientific Work}

He was born in Zemun, on August 31, 1903. Four grades of, at the time, elementary school he completed in Zemun, where he also started gymnasium but only completed the first grade. During the First World War, he received his education in France and Switzerland, where he completed the second through the sixth grade

Miloš Milovanović, doctor, Mathematical Institute of the Serbian Academy of Sciences and Arts. 
of gymnasium, and the seventh and the eighth grade along with the final examination he completed in 1921 in the town of his birth.

The same year he enrolls at the Department of Mechanical Engineering at the Technical Faculty in Gratz, but abandons it the next year, disappointed by the pragmatism of the instruction, that some professors emphasized in particular and with pride. His outstanding artistic soul, especially in fine arts, was looking for a profession imbued with art. For this reason, he enrolls at the architecture at the Technical Faculty in Belgrade, but stays there for only one semester; because Radojčić perceived art as a way of wisdom, and he did not find that studying architecture. In 1923, he transfered to the Mathematical group at the Faculty of Philosophy in Belgrade where he graduated in 1925, since he was able to get credit for the work done while studying technique. In 1928, he got his Ph.D. from the Faculty of Philosophy for the doctoral thesis Analytical Functions Expressed in Terms of Convergent Series of Algebraic Functions.

Professor's Radojčić scientific activity deals for the most part with the theory of analytical functions and can be classified into three thematic circles. The first one Radojčić himself defined as expressing general multiform analytical functions, on any type of their domain in terms of convergent series of algebraic functions. At the very beginning of his career in his Ph.D. thesis, Radojčić gave his generalization of the well-known theorems of Weirstrass and Runge for the case of an analytical function on an arbitrary region of the corresponding Riemann's surface. Radojčić added on this result and improved it on many levels in his thesis and in a series of later articles published before and after the war. The final form of the result, which among other things contains the theorem stating that any analytical function on any region of its Riemann's surface can be uniformly approximated by a series of algebraic functions, can be considered as a maximum possible generalization of the above-mentioned theorems of Weireschtrass and Runge. It is important to say that those results of Radojčić represented for the long period of time the most important achievements in its field. It was only 20 years after the publishing of Radojčić's thesis that the German mathematician Helene Florak produced the results comparable by the importance and difficulty to those of Radojčić; however, her result only nicely complement those of Radojčić and cannot be, by any means, considered their substitute.

The second thematic circle dealt with the problem of dividing Riemann's surface into leaves, which was one of the basic problems of the geometric theory of functions during one period of its development. Radojčić proved many central theorems related to these complex problems and introduced a general approach to the process of dividing any Riemann's surface into leaves for the case of unbounded Riemann's surface, when it is possible to talk about such a division in the usual sense. According to the competent opinion of the German mathematician E. Urlich, those theorems achieved the maximum possible results within the realm of the applied method. These and other results, published for the most part in the journals of our Academy and University, did not receive the needed publicity, which in turn enabled the appropriate response of the international mathematical audience to the similar results obtained by almost identical method by Japanese mathematician Shimizu, who published his papers in the world known journal. Upon closer examination of those papers, however, one can form an impression that the priority should be on professor Radojčić's side, both in time and essence. Both Radojčić and Shimizu used those theorems as a base for their further studies of automorphous functions. According to one of the major Radojčić's results obtained during further investigations, every meromorphous function is in a certain sense automorphous. 
The third group of his papers deals with geometrical and topological properties of analytical function in the vicinity of essential singularities, with the special consideration of, so-called problem of the type of the Riemann's surface. This is about stating the criteria so that the Riemann's surface is of elliptical, parabolic, or hyperbolic type. Here, among other things, Radojčić offered two variants of conditions sufficient for Riemann's surface to be of parabolic or hyperbolic type.

All of these Radojčić's papers belong to the geometric theory of analytical functions. He can be considered as an independent pioneer of certain methodological concepts of the theory of analytical functions. Also, it can be said that certain geometrism, a subtle and fluid geometric spirit and thinking style, represents an important component and a deep dimension of both internal unity and continuity of professor Radojčić's scientific work and his overall figure as a mathematician. Actually, this spirit represents that life-forming center, whose fertile and inspiring glow permeates all areas of his mathematical work, including his invaluable contributions to the introduction, establishment and design of all forms of contemporary instruction of geometry at the University of Belgrade.

In 1938, after being promoted to assistant professor at the Department of Mathematics of the Faculty of Philosophy, Radojčić, parallel to lecturing in the theory of analytical functions, took upon himself the task of establishing the first course of synthetic geometry, entitled Elementary Geometry. In 1945, when the new curriculum was made, Radojčić proposed the introduction of two new geometric disciplines: descriptive and higher geometry. Such an ambitious plan could not be carried out that easily with an insufficient number of teachers. Radojčić took upon himself obligation to teach three geometric disciplines: descriptive, elementary, and higher geometry.

The course Elementary Geometry was not only the first systematic course of synthetic geometry, but also the first axiomatic course ever taught at the University of Belgrade. In his lectures, professor Radojčić started to develop a rigorous approach to defining concepts and proving theorems, an approach never previously applied at the University of Belgrade, that called for proving even the most obvious assertions not included in axioms. In a certain way, Radojčić presented in this course his own axiomatic approach to Euclidean geometry. Being of the opinion that the deductive method was more evident when the number of starting concepts was minimum possible, his starting concepts were the point and relations between and congruent. Since he defined the line and the plane using the order of points, in Radojčić's work axioms of order preceded axioms of belonging. In his book Elementary Geometry, based on this course, he pointed out that this approach was consistent with the using of set theory in building geometry, where the line and the plane are seen as sets of points, not as particular elements of space.

Radojčić's work on axiomatically establishing the special theory of relativity is also of great importance for the deeper understanding of his relationship with geometry. He considered Einstein's relativistic physics to be a return of geometry to the source of the experience of which it long ago descended and the once again established lost link between physics and geometry; the link that showed that actually geometry was a part of mathematical physics. In his discussion of geometry, he named this approach internal viewpoint, since it derived geometry from the immediate internal experience of physical reality, to which we also belong (Radojčić, 1951).

In the list of Radojčić's scientific works eight units are related to this area. The summary of this work is presented in the monograph "Une Construction Axiomatique de la Théorie de L'Espace-Temps de la Relativité 
Restreinte", published in the Special Editions of the Academy of Science and Arts in 1973. Since he published the first paper in 1933 and the final monograph in 1973, it is evident that his interest in the theory of relativity lasted for full 40 years.

Axiomatic establishing of the space-time continuum of the theory of relativity interested mathematicians since the beginnings of its existence. In the papers that followed, some authors accept for the most part already formed structures and apply them to the topic of their interest, resulting in a short paper and relatively small number of axioms. Radojčić, however, believes that the topic of such fundamental and elementary importance, such as kinematics of the theory of relativity, that involves elementary geometry as well, deserves an independent and, in the contemporary sense, elementary treatment. In this way, he starts with axioms that are, in their physical interpretation, closest possible to the observable facts, avoiding to use even the analogy with the axiomatic system of the elementary geometry.

Guided by his own language minimalism, Radojčić chooses for his basic concepts signals or flashes of light, named "instantaneous events" and points they originated from or can be seen at, named "material points". Along with these two concepts, there are three basic relations: to happen, to be seen, and before. The whole theory is based on five basic concepts and 27 axioms classified into nine groups. Radojčić derives Lawrence's transformations for light-metric bodies as a logical consequence of basic geometric properties of the spread of the light. In this way, Lawrence's transformations are totally independent from the physical experiment, to the point that they cannot be even overruled by the experiment. Experiments are required only to establish whether solid bodies, which provide on Earth the base for all measurements, even cosmical events, have properties of light-metric bodies. The affirmative answer to this question, stating that solid bodies are indeed systems of light-metric bodies, already lies in the fact that every spectral line measured in the matter of solid state aggregation, has the constant wave length.

The work of professor Radojčić was neither the first nor the only breakthrough made by Serbian scientists into the geometric kernel of the theory of relativity. Already in 1910, Vladimir Varićak, professor at the University of Zagreb, highly versed in non-Euclidean geometry, gave an interpretation of the special theory of relativity in the geometry of Lobachevski (Kurepa, 1948). The following year, in 1911, he reaches a completely new understanding of the connection between those two theories and proves that, just as the Newtonian kinematics is derived from the Euclidean geometry, so can the basic theorems of Einstein's non-Newtonian kinematics be derived from the geometry of Lobachevski. The work of professor Radojčić, along with papers of Vladimir Varićak represented rare contribution of our science to the theory of relativity.

In 1959, professor Radojčić left the country. It is speculated that the reason lies in his inability to withstand the socio-political reality of the time he lived in, the reality that inundated also the University of Belgrade. He used the United Nations announcement about the scientific-technical aid to the undeveloped countries of Africa and Asia and from 1959 until 1964 worked as a professor at the University of Khartoum, Sudan. After that he moved to the National Center for Scientific Research in Paris, residing in a small town Thonon-les-Bains near Swiss border. There he died on May 14, 1975.

With the exception of scientific papers and text books, everything that Miloš Radojčić published appeared before the German occupation of Yugoslavia. Nevertheless, his unpublished documents still exist at one of his friends in the Swiss town of Dornach, near Basel. Some tens of thousands of pages on cosmology, biology, 
philosophy, poetry, history, religion, literary interpretations and literary translations, and studies, and more wait to be processed and, in a meaningful way, offered to readers ${ }^{1}$. In his written legacy, there are no papers related to mathematics (Dacić \& Mateljević, 2004).

\section{Anthroposophical Doctrine}

Anthroposophy is a mystic doctrine based on the teaching of Austrian philosopher, scientist, and artist Rudolf Steiner. Steiner was initially the secretary general of the Theosophist society ${ }^{2}$ for Germany, but he felt that the theosophist teaching was too much under the influence of Hinduism and Buddhism. Therefore, he felt a need to reveal a spiritual path in the authentic tradition of the West, an endeavor he carried on until his death. He was looking for a spiritual understanding of philosophy that enabled perceiving the world and the history of mankind as a consequence of the influence of higher forces — spiritual beings, which led the mankind step by step on the evolution ladder. During his life, he wrote more than 20 books and gave great number of lectures, resulting in over 360 volumes of his collected works.

Professor Radojčić was an anthroposophist. In anthroposophy he saw the aspiration of his time to the conscious revival of the primordial spirit of life in the midst of all-devouring desert of materialism. In particular, he emphasized the aim of anthroposophy to conduct its research in a spirit that permeated the contemporary culture, i.e., the scientific spirit. What is important for characterization of the spirit of contemporary culture is less the state of religion, even arts and more the state of the science. The force of that spirit was most completely realized in the contemporary physics and it is very significant coincidence that the appearance of anthroposophy coincided with the rapid advances in physics at the beginning of the 20th century. This sets anthroposophy apart from both a dreamy utopism and non-critical acceptance of the given truths, both being an expression of a way a spirit is enslaved by a soul's lower forms.

Among numerous anthroposophist papers on various topics a special place holds the paper "On Our Medieval Painting's Magical World”, published in the magazine National Defense in 1940. The text reveals a thinker of an extraordinary spiritual courage ready to guide the reader all the way to the frontier where individual consciousness touches horizons of all mankind and all times, by journeying deep inside himself in search for the secret of the time long gone. Without doubt, this text is one of the best studies of medieval painting ever written.

Over the centuries - he says - not only do the external circumstances of life change, but also the world inside a man and that change is deeper and more dramatic than ever thought in our time. From one century to the other, not only do customs, beliefs and all that enters the soul from the outside change but also the soul's abilities and spiritual powers. Thus, we are separated from the Middle Ages by a very concrete spiritual gap, which prevents us from comprehending the medieval art in the contemporary cultural and civilization context.

What roams around in the consciousness of today's painter, "problems" that preoccupy him, did not even exist in the soul of a medieval painter of ours and vice versa: what bothered a painter of that time during the sleepless nights, spent

\footnotetext{
1 In January, 2012, Mathematical Institute of the Serbian Academy of Sciences and Arts received photocopies of all these papers.

2 Theosophist society was founded in 1875 aiming to promote the thinking system developed in the papers of Helena Blavacka. Theosophy claims that all religions are attempts to assist the mankind in reaching the higher perfection by "spiritual hierarchy" and consequently, that every religion contains a part of the truth. Practically, this religious syncretism is mainly characterized by meditative techniques of India and Far East, through which it made a far-reaching impact on world culture by spreading them even in the countries they came from and where they were far from being widely used.
} 
praying or lights of his vision that illuminated him throughout his earthly life, all that, naturally, does not exist for the contemporary painter. It has to be said: in spite of us standing today face to face with a new, powerful wave of spirituality, such a form of soul and spiritual life that once existed will never again provide a foundation of the art of painting; because mankind moves forward, through deaths and resurrections, and future spirituality will never be the same as the one that passed. (Radojčić, 1940, p. 42)

While becoming absorbed in the mood that our old painting awakes, Radojčić notices the sentiment close to the feeling of an evening, a sunset, an evening twilight, even a night.

Already with first impressions that our old paintings provoke, we are overcome by a feeling of twilight; perhaps not because paintings tarnished of the century long fume of wax candles and icon lamp, but because it is really twilight that is being painted. All that is happening, happens at twilight, even when the painter did not have the evening on his mind, but a day or a night. On those paintings there is no real day to be found: in every day there is a mysterious presence of night or an evening day. And night is not that dark, but filled with visions of an unearthly day. (Radojčić, 1940, p. 43)

The answer to the question why is this, he finds in souls of painters of that time. While dealing with the general progress of the mankind, he points out that the ancient human consciousness bears high resemblance to the world of dreams. It was that the human soul was filled with sights that spoke instead of logical thoughts and that was one all-encompassing primordial clairvoyance. Spiritual depths or heights of the universe, reachable neither by senses nor plain thinking, were within reach of such clairvoyance. Over many a century that clairvoyance slowly faded and its innate place was overtaken by a freedom, which logical, critical thought brought along. Various ancient religious texts foresee this eclipse of clairvoyant powers and describe it as a night, through which the mankind would have to pass. It is that night that Radojčić recognizes as the appearance of materialism at the beginning of modern times. Relative to this night, the late Middle Ages represent hours of an evening twilight. Those are the hours of the ancient clairvoyance's twilight, in the last glistening of colors prior to total darkness.

Radojčić then writes about one strange occurrence-days and nights befriend each other in the same painting, as it is often seen on our old frescoes. The earth emits light from its strange rocks and objects on it and the sky is dark blue, like during the night. This is because old painters aspired not to paint the external world, but to pour the depths of their soul into paintings. The earthly world with its external light eclipses the splendor of the internal worlds. The painter's soul was being obsessed by this and thus, that surfaced also on the walls. Sky of the day would tell a story that the external light denied the human eye the depth of dark abysses of the universe, that the sky is closed, that it accepts neither a cry nor a prayer. But this is not how a pious medieval man felt. For him, the dark abyss was nearby, day and night. To the extent that the medieval man aligned himself with the dazzling sights that paid visits to people in older times, while the ancient clairvoyance was still awake, this dark abyss served him just right.

Entering the world of shapes, Radojčić discovers, for us, unusual geometric law that he calls counter perspective. This is a phenomenon that, contrary to our usual sense of space, where two parallel lines get closer in the distance, on medieval paintings exactly the opposite happens: as they get further from the observer, parallel lines get further from each other as well. Instead of ascribing this aberration to the poor skillfulness of the medieval painter, Radojčić meets it halfway and asks himself where does the idea of perspective in painting of modern time and modern geometric consciousness come from. 
Roughly speaking, word perspective translates from Latin as: looking through something, transparency, in other words seeing through the depths of the space distances. In its nature, the painting does not exist in a space, but in a plane. Nevertheless, the perspective strives to create an illusion of three-dimensional space even in a two-dimensional plane. It is therefore only with the perspective that painting, in a certain sense, moves from the plane into the space; from its two-dimensional non-material world into our plain world of three-dimensions. "Is it not that the world of paintings is a separate world?"- The painter of the time passed would ask us and if he could, in modern sense, explain his feelings, maybe would add the following: "Architecture and sculpture must answer to the space, painting must not. The painter, in his field, strives to express spiritual impressions. The painter of Middle Ages needs only that which reveals to the eye something about a soul and a spirit. If your perspective is such, give it to me. But lo and behold—with your perspective you do not wish to express an internal impression, but the external sensation of looking into the space." And really, our desire to paint true to perspective is rooted in the desire of these natural-scientific and materialistic times that we stay true first and foremost to the external perception of the external world. On the contrary, "wrong perspective"-I would say "counter perspective" of our old painters is rooted in the desire that a man remains true first and foremost to an internal sensation, an impression of the internal world. (Radojčić, 1940, p. 44)

A desire that a man remains true to an external sensation, characteristic for the modern times, causes our and painter's eye to resemble that of a hunter, who aims - measures. This either did not exist in old painting or, if it did, existed on a much smaller scale. First, there were rules posed by medieval symbolism. Second, the real medieval painter painted out of pure sentiment, not connected to the outside world. The painting, as if out of a dream, descended on a wall. A dream is a cradle of reality and this is what medieval painter wants to proclaim with his art. The world we inhabit in reality is not introverted, but it opens up to infinity. On all sides one small, narrow gap of infinity opens up. What is far away is large, because it transforms into pure spirit, into stellar dimension; what is close is small, because it is confined to the earthly world. According to that old perspective, everything that recedes from the earth to infinity becomes larger.

Such a deep, intuitive grasp of the meaning of basic geometric terms and laws is, no doubt, in the foundation of Radojčić's scientific work. Generally speaking, the object of his scientific work is geometry; either a geometric theory of functions, the research of geometry of Riemann's surfaces or geometric foundation of the theory of relativity, where Radojčić did not treat geometry as an abstract, formal-logical construct, but first and foremost as a branch of mathematical physics. Furthermore, he treated physics as a spiritual science that reveals internal laws of a being, which even the matter itself freely abides by. In his text, published in 1956, about Albert Einstein, he portrays Einstein as a revolutionary hero who took space and time out of invisible shackles of scientific thought and enabled a unifying understanding of the whole physical world, an understanding never imagined before him (Radojčić, 1956). The point is that Einstein's theory places the observer in the center of physical system, and defines space-time relations as subjective perception mediated by light signals. In the same way, counter perspective places the observer in the center of image deriving geometry from subjective perception and the medium is again light, but the light of divine revelation.

In addition to counter perspective, Radojčić notices one more relativistic phnomenon in the painting of Middle Ages. If a painter of today wishes to present two episodes of an event, he will paint either two paintings or only one episode, sacrificing the other. The medieval painter, so close to the vivid, imaginative point of view, wanted to portray fluid, ever-changing pictures of his awaken dreaming as immediate as possible, including the possibility that one being or an object is seen on two different places at the same time. While painting in this way, he was at ease with synthetic compression of time to the same extent as we are at ease with analytical splitting it into moments. 
Giving an instantaneous picture of an event means imposing stationary position to something that is not stationary. To a certain degree, this is an illusion similar to representing different moments in the same picture. It is only that we are, with our habits and at the present level of the evolution, closer to the first illusion than the second. On the contrary, old painters felt that both illusions carry certain truth within. In the world of life, no form stays motionless, but it changes, ever so slightly, just like pictures in dreams. It is such forces that old painting has. In the soul of an observer, it provokes magical metamorphoses that speak of secret connections in the deeper nature of the world.

The power of such metamorphoses is most strikingly seen on the earth's relief that is in the background or on the ground in many paintings. Cracked, broken, and bare stone mountains rise ever steeper towards the summit and resemble jagged waves. Formed in this way, it seems that they would like to remind us that the world of solid matter was once liquid, not only in the sense of contemporary science but also in the spiritual sense, meaning that the kingdom of matter is frozen kingdom of the ancient life cursed into a dream of death.

How much secrecy there is in the way how, right after the first sudden rise, all those mountains break down into abyss in front of an empty, dark sky. A man has an impression that the "end of the world" is right here, very near and that with the bodily eyes one stares into a void, into nothingness; with the spirit, though, into an interminable sea of spirit. On some painting, on the contrary, it seems that the hard stone disappears into the dark blue, as if the sky melts it, forming statically impossible shapes, similar to ice bergs melting in the sun.- O Oh, those magical feelings, so terrifying to the times that skim the surface, so familiar to the medieval souls immersed into a spiritual sea. (Radojčić, 1940, p. 45)

This is exactly the same claim that the real geometry is in its essence fractal, which almost half a century later Mandelbrot developed in his famous book ${ }^{3}$. In the context of the quoted paragraph, one can understand better Radojčić's interest in the geometric theory of functions, especially in the behavior of analytical functions in the vicinity of essential singularities ${ }^{4}$. From this viewpoint, his personality comes through as a road of integral consciousness, unreachable to the world hopelessly splitted into an artistic dream and a scientific reality. All of his anthroposophist texts emphasize the thought that it is only through an artistic sensation that one can reach the knowledge, that is made of much more than only empty abstractions and external sensory experience.

The language of dreams - the language of art is the language of life itself. The life contains all terms, but it is not contained in any one term. It is only with such knowledge that we may approach the search for meaning in the echoes of ancient shrines.

\section{Digitization}

The digitization of the works of professor Radojčić started with his Ph.D. thesis, which was digitized in July of 2008 at the mathematical Institute of the Serbian Academy of Science and Arts. Also digitalized works are his papers about geometric theory of functions, anthroposophist texts, and monograph about axiomatic foundation of

\footnotetext{
${ }^{3}$ The idea of fractal was introduced in 1975 by B. Mandelbrot. Under fractal, he understood certain singular mathematical objects that do not adhere to the topological theory of dimensions. The word fractal comes from Latin term fractus, which means broken, but also irregular in the sense of fragments. In his book Fractal Geometry of Nature in 1982, he claims that the majority of natural phenomena cannot be described using objects of classical geometry, because in its essence, the nature is a fractal phenomenon.

${ }^{4}$ Singularities of a function are points where function behaves in a unique matter, which excludes them from the general investigation of the function's behavior in a certain area. In complex analysis, the points of essential singularity are the points where a function behaves irregularly to the extent that there is no limit of a function at that point. Those are the points of abyss, where a function experiences an irreparable breakage, just as the quoted paragraph describes.
} 
the special theory or relativity and textbooks General Mathematics and Elementary Geometry. All this is exhibited as a part of the virtual library of the National Center for Digitization (retrieved from http://elib.matf.bg.ac.yu:8080/virlib/). Papers published in Publication de l'institute mathematique can be found on page (retrieved from http://elib.mi.sanu.ac.rs/pages/browse_journals.php).

It would be important to digitize his unpublished works, so that a broad circle of experts could evaluate them. Among the unpublished works, a special value holds the original translation and interpretations of The Gospel According to John, of which one professor of the Faculty of the Ortodox Theology gave opinion saying that the writer's knowledge of Serbian language was extraordinary, that his theological education was enviable and that many parts of interpretations were magnificent.

\section{Conclusions}

In the brave endeavor to write about such a complex and ingenious personality like Miloš Radojčić, the author was trying to speak using his own words and the words of those who knew him. Therefore, listed below are some of his texts, out of which, without hesitation, the author took over whole sentences. The complete bibliography of Radojčić can be found in the book Quiet and Earnest Prayer of Miloš Radojčić (Tiha i usrdna molitva Miloša Radojčića) (1995). In that book, there are also newly printed papers Albert Einstein and His Time (Albert Ajnštajn i njegovo doba) (1956) and On Our Medieval Painting’s Magical World (O čarobnom svetu našeg srednjevekovnog slikarstva) (1940), as well as couple of texts about him, that I did not specifically annotate.

It should be noted that Radojčić, in many respects, was ahead of his time, and that at the beginning of the 21 st century, some of his papers, both published and unpublished ones, are extremly actual. Their republishing, in that sense, could be very important both for scientific and for general public as well.

\section{References}

Adamović, D., \& Lopandić, D. (1976). Dr. Miloš Radojčić. Matematički vesnik, 13(28), 245-252.

Dacić, R., \& Mateljević, M. (2004). Life and work of Serbian scientists-Miloš Radojčić (Život i delo sprskih naučnika—Miloš Radojčić) (pp. 207-242). Beograd: SANU.

Jugoslovensko Antroposofsko Društvo (1931-1940). Come to know yourself-Journal for anthroposophy and art (Upoznaj samoga sebe-Č́asopis za antroposofiju i umetnost). Beograd: Jugoslovensko antropozofsko društvo.

Kurepa, Đ. (1948). Vladimir Varićak. Glasnik mat, fiz. i Astr., 3, 64-76.

Radojčić, M. (1929). On the poem “Dungeon” by Vladislav Petković-Dis (O Disovoj Tamnici). Beograd: Jugoslovensko Antroposofsko Društvo-Biblioteka Lepih Nauka.

Radojčić, M. (1940). On our medieval painting's magical world (O čarobnom svetu našeg srednjevekovnog slikarstva). Narodna Odbrana, 10, 42-45.

Radojčić, M. (1951). About viewpoints in geometry (O stanovištima u geometriji) (pp. 37-48). Prvi kongres mat, fiz. i astr. SFRJ, Bled 8-12. 1. 1949, knjiga 2. Beograd.

Radojčić, M. (1956). Albert Einstein and his time (Albert Ajnštajn i njegovo doba) (pp. 160-170). Godišnjak Našeg Neba, Matematički Institut SAN, Beograd.

Radojčić, M. (1961). Elementary geometry (Elementarna geometrija. Osnovi i elementi Euklidove geometrije). Beograd: Naučna Knjiga.

Radojčić, M. (1973). An axiomatic construction of the theory of space-time in the relativity approach (Une construction axiomatique de la théorie de l'espace-temps de la Relativité Restreinte). Serbe des Sc. Et des Arts, Monographie, t. CDLXII, 165.

Tomić, M. (1976). Miloš Radojčić. Godišnjak SANU, LXXXII, 194-196.

Trifunović, D. (1995). Quiet and earnest prayer of Miloš Radojčić (Tiha i usrdna molitva Miloša Radojčića). Beograd: Narodna Knjiga ALFA. 